US Army Corps of Engineers ${ }_{\circledast}$

\title{
The Influence of Dissolved Organic Carbon on Acute Lethality in Zebrafish (Danio rerio) Exposed to Silver Nanoparticles and Silver Nitrate
}

by Adam D. Hawkins, Cammi Thornton, Will Guyton, Jacob K. Stanley, Alan J. Kennedy, Jeffery A. Steevens, and Kristine L. Willett

PURPOSE: This technical note describes the relationship of acute lethality between citrate or polyvinylpyrrolidone (PVP) coated silver nanoparticles (AgNPs) and silver nitrate $\left(\mathrm{AgNO}_{3}\right)$ to varying concentrations of dissolved organic carbon (DOC). The results of this relationship were obtained to provide a data set that supports the Environmental Modifying Factors Tool in NanoExPERT (http://nanoexpert.usace.army.mil/), a suite of tools that were developed within the nanomaterial risk assessment focus area at the U.S. Army Engineer Research and Development Center (ERDC) to aid in environmental risk assessment.

BACKGROUND: Due to the known toxicity of silver to aquatic organisms (Wood et al. 1999), an understanding of the possible risk associated with the increased use and subsequent release of AgNPs in the aquatic ecosystem is needed. While an increasing number of studies are available on the toxicity of silver nanoparticles (Bondarenko et al. 2013), few have established toxicity patterns relative to environmentally relevant alterations in water chemistry parameters (e.g., Kennedy et al. 2012; Kennedy et al. 2014; Harmon et al. 2014; Gao et al. 2009). Although laboratory exposures that consider AgNP toxicity only in a single water type are crucial to understanding the mechanisms of toxicity, proper assessment of risk requires consideration of complex environmental matrices that transform and affect the toxicity of AgNPs (Lowry et al. 2012).

NanoExPERT (http://nanoexpert.usace.army.mil/) is a suite of tools developed within the nanomaterial risk assessment focus area at ERDC to predict potential environmental risks associated with nanomaterial use. Although applications of NanoExPERT extend past the Department of Defense and can aid the safe development of consumer products, an expansion of toxicity data is needed to more accurately estimate environmental risks. One such need is to address uncertainties of AgNP toxicity in varying water chemistry parameters, such as DOC, ions, and $\mathrm{pH}$ to provide more accurate toxicity predictions in actual environmental matrices.

The known toxicity of the $\mathrm{Ag}^{+}$ion and its identification as the primary cause of acute toxicity of aquatic organisms (Kennedy et al. 2010) makes identification of ion release potentially vital to understanding AgNP toxicity. Water chemistry parameters can also affect aggregation and dispersion, which results in changes to expected toxicity (Gao et al. 2009; McLaughlin and Bonzongo 2012). One such water chemistry parameter that can modify nanosilver toxicity is the presence of DOC. Increased DOC decreases toxicity of AgNPs by stabilizing the particles in zooplankton (Ceriodaphnia dubia) (Kennedy et al. 2012) and in bacteria (Pseudomonas fluorescens) via 
complexion of $\mathrm{Ag}^{+}$ions (Hogstrand and Wood 1998). When fathead minnows or juvenile rainbow trout were exposed to ionic silver in water with increased DOC levels, the 96-h lethal concentrations $\left(\mathrm{LC}_{50}\right)$ values significantly increased in both species (Bury et al. 1999), which indicates a reduction in toxicity. While these studies establish that DOC presence can mitigate silver toxicity, greater understanding is still needed when considering various fish species and AgNP sizes.

In order to accurately predict the toxicity of AgNPs, laboratory-based exposures must take into consideration the actual environmental conditions in which AgNPs can be found. During a data compilation conducted by the Nickel Producers Environmental Research Association (NiPERA), the Rhine River was found to have a DOC of $2.8 \mathrm{mg} / \mathrm{L}$ (NiPERA Inc. 2015). Similarly, the United States Geological Survey determined that the Snake River in Yellowstone National Park, Wyoming contained a DOC of 0.9 to $4.5 \mathrm{mg} / \mathrm{L}$, Panther Creek contained a DOC between 1.1 to $4.6 \mathrm{mg} / \mathrm{L}$ (Mebane 2008), and the Suwannee River contained a DOC between 2.3 and $45.7 \mathrm{mg} / \mathrm{L}$ (Gao et al. 2009). Based on natural occurrences in the environment as reflected by these four bodies of water, an environmentally relevant DOC range would be $0-40 \mathrm{mg} / \mathrm{L}$.

In this study, the authors aimed to improve estimates of aquatic toxicity of nanoparticles to fish by establishing median $\mathrm{LC}_{50}$ of citrate and PVP-AgNPs (nominally $20 \mathrm{~nm}$ ) within increasing, but environmentally relevant, DOC concentrations of $1,5,10,20$, and $40 \mathrm{mg} / \mathrm{L}$ using a common freshwater model, larval zebrafish (Danio rerio). Then, the results were integrated into the Environmental Modifying Factors Tool in the NanoExPERT tool suite.

\section{MATERIALS AND METHODS}

Fish source. Zebrafish, $\mathrm{AB}$ line wild-type, were purchased from the Zebrafish International Resource Center (ZIRC, Eugene, OR, USA). The fish were kept under the University of Mississippi Institutional Animal Care and Use Committee approved protocol. Keeping with the guidelines, the fish were raised in an Aquatic Habitats ZF0601 Zebrafish Stand-Alone System (Aquatic Habitats, Apopka, FL, USA) with pH 7.0-7.5 and salinity of $60 \mathrm{ppm}$ in zebrafish water. Each habitat was kept between $25^{\circ} \mathrm{C}$ and $28^{\circ} \mathrm{C}$ with a $14: 10$ light-dark cycle. The zebrafish were fed live brine shrimp (Artemia sp.) and TetraMin ${ }^{\circledR}$ Tropical Flakes (TertraMin, Blacksburg, VA) twice daily. The sexually mature breeders selected had no signs of disease or deformities. Eggs were collected using a receptacle at the bottom of the habitat that allowed the eggs to fall into the egg reservoir, while preventing the zebrafish from interfering with the fertilized eggs (Fang et al. 2013).

Moderately hard water. Moderately hard water (MHW) was made according to U.S. Environmental Protection Agency (EPA) guideline 821-R-02-013 by adding $1.20 \mathrm{~g}$ of $\mathrm{MgSO}_{4}, 1.92 \mathrm{~g} \mathrm{NaHCO}_{3}$, and $0.080 \mathrm{~g} \mathrm{KCl}$ to $19 \mathrm{~L}$ of deionized water, and the solution was aerated overnight. $\mathrm{CaSO}_{4} \cdot 2 \mathrm{H}_{2} \mathrm{O}(1.2 \mathrm{~g})$ was added to a separate $1 \mathrm{~L}$ of deionized water, and the solution was mixed until the $\mathrm{CaSO}_{4}$ was dissolved completely. Once dissolved, the $\mathrm{CaSO}_{4}$ solution was added to the $19 \mathrm{~L}$ of MHW, stirred, and aerated continuously for 24 hours until well mixed and equilibrated.

Silver. $\mathrm{AgNO}_{3}$ was obtained from a commercial source (Sigma Aldrich, St. Louis, $\mathrm{MO}$ ) and diluted to a working stock in nanopure water with a nominal concentration of $10 \mu \mathrm{g} / \mathrm{mL}$. PVPAgNPs and citrate-AgNPs were obtained from Nano Composix (San Diego, CA, USA) at a concentration of $1 \mathrm{mg} / \mathrm{mL}$ and a nominal size of $20 \mathrm{~nm}$. Concentrated stock suspensions were 
prepared by sonicating the sample mixture in a water bath for 5 minutes and inverting multiple times to mix. Concentrated stocks were diluted with nanopure water to obtain a working stock with a nominal concentration of $40 \mu \mathrm{g} / \mathrm{mL}$. Field Flow Fractionation (PostNova F-1000 symmetrical flow Field Flow Fractionation, St. Lake City, UT) was used to verify particle size. The concentrations of silver used during the DOC exposures were confirmed with inductively coupled plasma mass spectrometry (ICP-MS), and the $\mathrm{LC}_{50}$ calculations were performed using measured silver concentrations that ICP-MS determined.

Dissolved organic carbon. The dissolved organic carbon, Suwannee River extract, was purchased from the International Humic Substances Society (IHSS, Atlanta, GA). A mass of 40 mg of Suwannee River extract was added to one liter of MHW and filtered through a 45 micron filter to remove the undissolved portion. The remaining mixture was then diluted to nominal concentrations of $1,5,10,20$, and $40 \mathrm{mg} / \mathrm{L}$. The USDA National Sedimentation Laboratory (USDA-NSL, Oxford, MS) verified DOC concentrations.

Zebrafish LC 50 exposures. After 48 hours post fertilization, hatched larvae were verified to be alive by heartbeat. One larva per well was placed in a 96 well plate. The exposure was started with the addition of nominal 1, 10, 20, 40, 60, 80, 100, and $200 \mu \mathrm{g} / \mathrm{L}$ of $\mathrm{AgNO}_{3}$ or 400, 800, 1200,1600 , and $2000 \mu \mathrm{g} / \mathrm{L}$ in AgNP exposures.

For each exposure, 20 larval zebrafish were exposed to each condition (i.e., 20 zebrafish were exposed to a DOC $40 \mathrm{mg} / \mathrm{L}$ at an $\mathrm{AgNO}_{3}$ concentration of $100 \mu \mathrm{g} / \mathrm{L}$ ). After dosing the zebrafish, the 96 well plates were wrapped in aluminum foil in order to protect AgNPs from increased aggregation due to UV light (Cheng et al. 2011). The foil-wrapped plates were placed in an incubator at $26^{\circ} \mathrm{C}$. At 96 hours post fertilization (a total of 48 hours of exposure), the plates were removed from the incubator, examined under an Olympus BX-40 microscope (Olympus Americas, Center Valley, PA), and the number of dead fish were determined by the absence of cardiac activity and recorded. The acquired data were entered into the EPA's LC 50 calculation program (http://sdi.odu.edu/model/lc50.php).

RESULTS: ICP-MS analysis (Table 1) confirmed all aqueous silver concentrations. PVP-AgNP concentrations agreed closely with the nominal concentrations, while citrate-AgNP concentrations were lower than the expected nominal concentration. Actual DOC concentrations closely agreed with the expected nominal DOC concentrations (Table 2). Hydrodynamic diameters of particles by dynamic light scattering were $28 \pm 4 \mathrm{~nm}$ and $26 \pm 3 \mathrm{~nm}$ for citrateAgNPs and PVP-AgNPs, respectively. All three silver treatments were the most toxic at $0 \mathrm{mg}$ $\mathrm{DOC} / \mathrm{L}$, with $\mathrm{LC}_{50}$ values of 36,448 , and $826 \mu \mathrm{g} / \mathrm{L}$ for $\mathrm{AgNO}_{3}$, citrate-AgNPs, and PVP-AgNPs, respectively (Figure 1). Toxicity decreased in all treatments as the DOC concentration increased. The lowest toxicity was measured at the highest DOC tested $(40 \mathrm{mg} \mathrm{DOC} / \mathrm{L})$, with $\mathrm{LC}_{50}$ values of 106, 880, and $1670 \mu \mathrm{g} / \mathrm{L}$ for $\mathrm{AgNO}_{3}$, citrate-AgNPs, and PVP-AgNPs, respectively.

The mechanism of toxicity of the silver ion $\left(\mathrm{Ag}^{+}\right)$to aquatic organisms was previously studied (Morgan et al. 1997). The toxicity of AgNPs is thought to be derived from the dissociation of free silver ions from particles (Newton et al. 2013; Kennedy et al. 2010). These free silver ions are produced as the equilibrium allows, which is determined, in part, by the water chemistry parameters of the aquatic environment. Therefore, there can be varying toxicities from AgNPs of the same size and/or water concentration when water chemistry parameters are changed. 
Table 1. Nominal versus measured silver concentrations in water for experiments with DOC (mean and standard deviation).

\begin{tabular}{|lcc|}
\hline \hline \multirow{2}{*}{ Nominal $(\mu \mathrm{g} / \mathrm{L})$} & \multicolumn{2}{c|}{ Measured $(\mu \mathrm{g} / \mathrm{L})$} \\
& PVP-AgNPs & Citrate-AgNPs \\
\hline 400 & $465 \pm 4$ & $346 \pm 11$ \\
800 & $781 \pm 41$ & $600 \pm 20$ \\
1200 & $1124 \pm 58$ & $871 \pm 55$ \\
1600 & $1526 \pm 25$ & $1126 \pm 59$ \\
2000 & $1915 \pm 30$ & $1386 \pm 72$ \\
\hline
\end{tabular}

Table 2. Nominal versus measured DOC concentrations. Note: measured DOC concentrations are $40 \%$ of the nominal total concentration of natural organic matter powder added (mean and standard deviation).

\begin{tabular}{|cc|}
\hline \hline Nominal DOC $(\mathrm{mg} / \mathrm{L})$ & Measured DOC $(\mathrm{mg} / \mathrm{L})$ \\
\hline 40 & $38.6 \pm 1.2$ \\
20 & $22 \pm 0.9$ \\
10 & $11 \pm 1.5$ \\
5 & $6.6 \pm 0.2$ \\
2.5 & $2.3 \pm 0.3$ \\
0 & $1.4 \pm 0.3$ \\
\hline
\end{tabular}




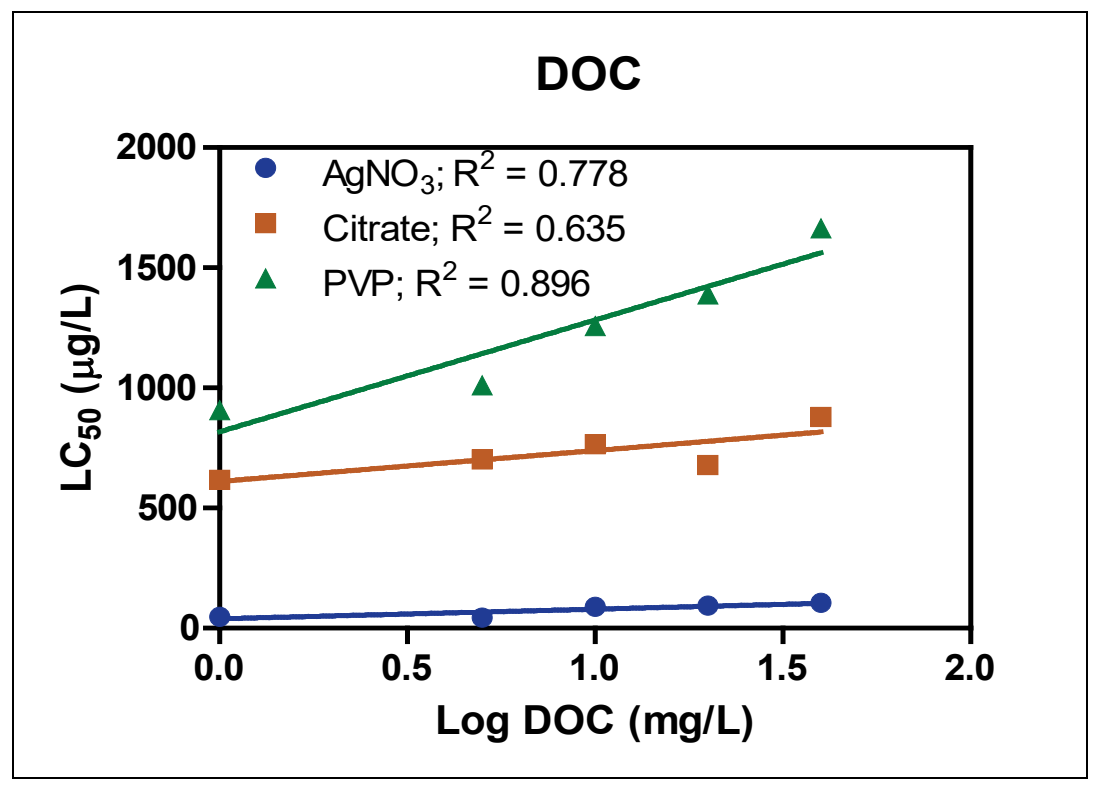

Figure 1. Lethal concentrations for $50 \%$ of organisms ( $\left.\mathrm{LC}_{50} \mathrm{~S}\right)$ after exposure to $\mathrm{AgNO}_{3}$, citrate-AgNPs, or PVP-AgNPs in varying concentrations of DOC.

In embryo and larval fish, exposure to the $\mathrm{Ag}^{+}$ion and AgNPs has decreased swim bladder inflation, hatching and survival rates, and altered embryo activities (Powers et al. 2011; Powers et al. 2010). Developmental abnormalities in the eyes and central nervous systems were observed in larval Japanese medaka (Oryzias latipes) (Kashiwada et al. 2012) and zebrafish (Yeo and Kang 2008) after exposure to AgNPs. Decreased hatching rate and survival were also common after AgNP exposure (Christen et al. 2013; Asharani et al. 2008; Powers et al. 2011).

In this study, as expected, increasing concentrations of DOC reduced the lethality of AgNPs and $\mathrm{Ag}^{+}$as $\mathrm{AgNO}_{3}$. The results were consistent with previous findings, which showed reduced toxicity in the presence of DOC in Ceriodaphnia dubia (Kennedy et al. 2012; Kennedy et al. 2014), Pseudokirchneriella subcapitata (McLaughlin and Bonzongo 2012), and Daphnia magna (Gao et al. 2012). While DOC coats AgNPs, which increases stability due to steric hindrance (Kennedy et al. 2012; Fabrega et al. 2011), the relationship of toxicity reduction of AgNPs and DOC is unclear. DOC coating could prevent dissolution or reduce toxicity by complexation of released ions (Erickson et al. 1998).

Integration into NanoExPERT. The data presented in this report provides a relationship between AgNP toxicity and varying DOC concentration. While these data only provide a small picture of DOC and AgNP interaction, utilization of these data combined with the work of others can lead to better risk prediction and understanding of toxicity. In order to make connections with other data and understand the broader picture, data must be combined in an easy to utilize central database. The NanoExPERT tool suite (http://nanoexpert.usace.army.mil/; Figure 2) was developed to support risk assessment of nanomaterials. Data resulting from these exposures contributed to the Environmental Modifying Factors Tool, which helps explain the effects of changes in water chemistry parameters and toxicity in a range of organisms (Figure 3). 


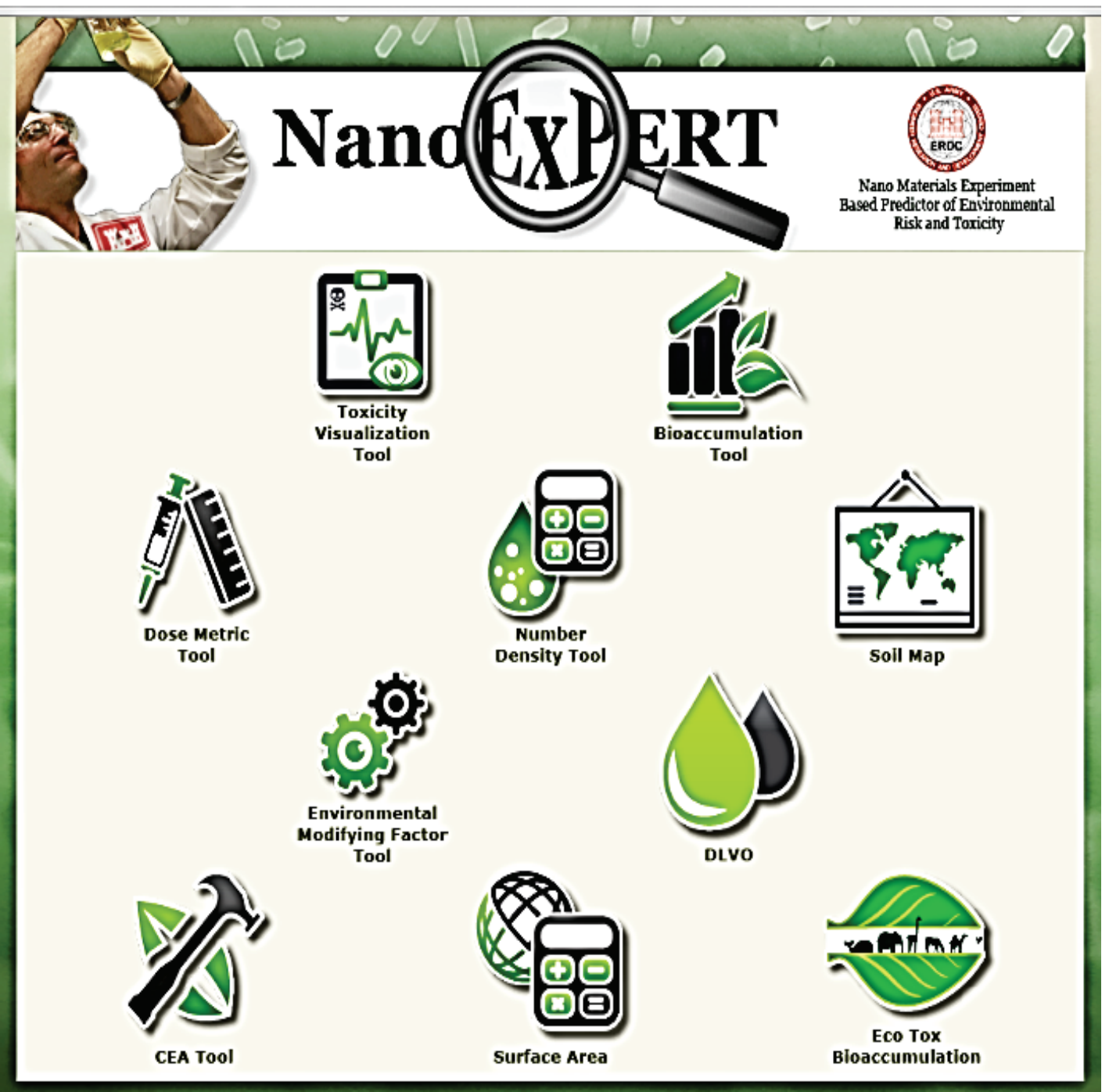

Figure 2. NanoExPERT Tool Suite. Screenshot of NanoExPERT tool, which displays the various tools available to aid in nanoparticle environmental risk assessment. Access: http://nanoexpert.usace.army.mill. 


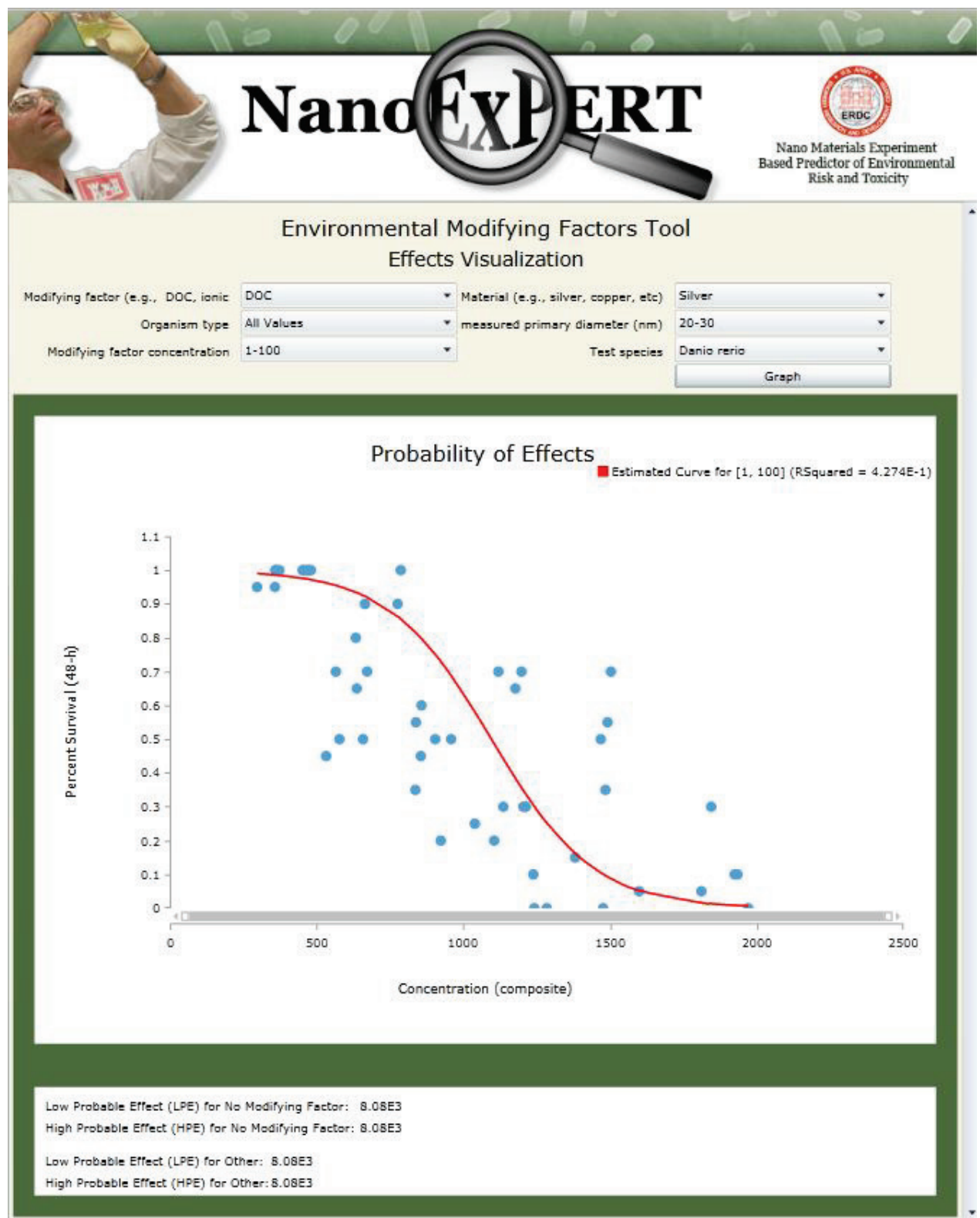

Figure 3. Environmental Modifying Factors Tool. Screenshot of DOC LC $5_{50}$ in zebrafish from the modifying factors tool with the data from this study integrated.

Further research is still needed to predict AgNP interactions with variations in other water chemistry parameters (e.g., varying $\mathrm{pH}$ and hardness), as actual aquatic ecosystems create a more complex scheme by which toxicity changes with multiple interactions occurring simultaneously.

SUMMARY: The objective of this investigation was to determine mortality of larval zebrafish after exposure to $\mathrm{AgNO}_{3}$, citrate-AgNPs, or PVP-AgNPs in varying concentrations of DOC. The results showed that increasing DOC decreased the toxicity of all silver formulations with $\mathrm{LC}_{50} \mathrm{~S}$ increasing from 36 to $106 \mu \mathrm{g} / \mathrm{L}$ in $\mathrm{AgNO}_{3}, 448$ to $880 \mu \mathrm{g} / \mathrm{L}$ in citrate-AgNPs, and 826 to 1670 $\mu \mathrm{g} / \mathrm{L}$ in PVP-AgNPs when DOC was increased from 0 to $40 \mathrm{mg} / \mathrm{L}$. The highest reduction in $\mathrm{LC}_{50}$, up to 2.9 fold, was detected in the $\mathrm{AgNO}_{3}$ treatments. These data were then integrated with 
other studies in the Environmental Modifying Factors Tool within the NanoExPERT tool suite to contribute to better environmental risk assessment of AgNPs in complex environmental matrices.

ADDITIONAL INFORMATION: This technical note was prepared by Dr. Adam D. Hawkins, Environmental Toxicology Research Program (ETRP), The University of Mississippi; Ms. Cammi Thornton, Research and Development Chemist, The University of Mississippi, ETRP; Mr. Will Guyton, Researcher, The University of Mississippi, ETRP; Dr. Jacob K. Stanley, Research Biologist, ERDC Environmental Laboratory (EL); Mr. Alan J. Kennedy, ERDC-EL; Dr. Jeffery A. Steevens, Senior Scientist, ERDC-EL; Dr. Kristine L. Willett, Professor of Pharmacology, The University of Mississippi, Department of BioMolecular Sciences. Contact Mr. Alan J. Kennedy at Alan.J.Kennedy@usace.army.mil for more information about this research or this report.

This research was funded by the Army Environmental Quality Technology Program (Dr. Elizabeth Ferguson, Technical Director). This Technical note should be cited as follows:

Hawkins, A. D., C. Thornton, W. Guyton, J. K. Stanley, A. J. Kennedy, J. A. Steevens, and K. L. Willett. 2017. The effects of dissolved organic carbon on acute lethality in zebrafish (Danio rerio) after exposure to silver nanoparticles and silver nitrate. ERDC/EL TN 17-1. Vicksburg, MS: U.S. Army Engineer Research and Development Center.

\section{REFERENCES}

Asharani, P. V., Y. L. Wu, Z. Gong, and S. Valiyaveettil. 2008. Toxicity of silver nanoparticles in zebrafish models. Nanotechnology 19(25):255102.

Bondarenko, O., K. Juganson, A. Ivask, K. Kasemets, M. Mortimer, and A. Kahru. 2013. Toxicity of Ag, $\mathrm{CuO}$ and $\mathrm{ZnO}$ nanoparticles to selected environmentally relevant test organisms and mammalian cells in vitro: A critical review. Archives of Toxicology 87(7): 1181-1200.

Bury, N. R., F. Galvez, and C. M. Wood. 1999. Effects of chloride, calcium, and dissolved organic carbon on silver toxicity: Comparison between rainbow trout and fathead minnows. Environmental Toxicology and Chemistry 18(1): 56-62.

Cheng, Y., L. Yin, S. Lin, M. Wiesner, E. Bernhardt, and J. Liu. 2011. Toxicity reduction of polymerstabilized silver nanoparticles by sunlight. The Journal of Physical Chemistry C 115(11): 4425-4432.

Christen, V., M. Capelle, and K. Fent. 2013. Silver nanoparticles induce endoplasmatic reticulum stress response in zebrafish. Toxicology and Applied Pharmacology 272(2): 519-528.

Erickson, R. J., L. T. Brooke, M. D. Kahl, F. V. Venter, S. L. Harting, T. P. Markee, and R. L. Spehar. 1998. Effects of laboratory test conditions on the toxicity of silver to aquatic organisms. Environmental Toxicology and Chemistry 17(4): 572-578.

Fabrega, J., S. N. Luoma, C. R. Tyler, T. S. Galloway, and J. R. Lead. 2011. Silver nanoparticles: behaviour and effects in the aquatic environment. Environ. Int. 37 (2):517-531.

Fang, X., J. Corrales, C. Thornton, B. E. Scheffler, and K. L. Willett. 2013. Global and gene specific DNA methylation changes during zebrafish development. Comparative Biochemistry and Physiology Part B: Biochemistry and Molecular Biology 166(1): 99-108. 
Gao, J., K. Powers, Y. Wang, H. Zhou, S. M. Roberts, B. M. Moudgil, B. Koopman, and D. S. Barber. 2012. Influence of Suwannee River humic acid on particle properties and toxicity of silver nanoparticles. Chemosphere 89(1): 96-101.

Gao, J., S. Youn, A. Hovsepyan, V. L. Llaneza, Y. Wang, G. Bitton, and J.-C. J. Bonzongo. 2009. Dispersion and toxicity of selected manufactured nanomaterials in natural river water samples: Effects of water chemical composition. Environmental Science and Technology 43(9): 3322-3328.

Harmon, A. R., A. J. Kennedy, A. R. Poda, A. J. Bednar, M. A. Chappell, and J. A. Steevens. 2014. Determination of nanosilver dissolution kinetics and toxicity in an environmentally relevant aqueous medium. Environmental Toxicology and Chemistry 33(8): 1783-1791.

Hogstrand, C., and C. M. Wood. 1998. Toward a better understanding of the bioavailability, physiology, and toxicity of silver in fish: Implications for water quality criteria. Environmental Toxicology and Chemistry 17(4): 547-561.

Kashiwada, S., M. E. Ariza, T. Kawaguchi, Y. Nakagame, B. S. Jayasinghe, K. Gärtner, H. Nakamura, Y. Kagami, T. Sabo-Attwood, P. L. Ferguson, and G. T. Chandler. 2012. Silver nanocolloids disrupt medaka embryogenesis through vital gene expressions. Environmental Science and Technology 46(11): 6278-6287.

Kennedy, A. J., M. A. Chappell, A. J. Bednar, A. C. Ryan, J. G. Laird, J. K. Stanley, and J. A. Steevens. 2012. Impact of organic carbon on the stability and toxicity of fresh and stored silver nanoparticles. Environmental Science and Technology 46(19): 10772-10780.

Kennedy, A. J., S. Diamond, J. K. Stanley, J. Coleman, J. A. Steevens, M. A. Chappell, J. Laird, and A. Bednar. 2014. Nanomaterials ecotoxicology: A case study with nanosilver. In Nanotechnology environmental health and safety: Risks, regulation, and management, Second edition, ed. M. S. Hull and D. M. Bowman, 117-151. Waltham, MA: William Andrew Applied Science Publishers.

Kennedy, A. J., M. S. Hull, A. J. Bednar, J. D. Goss, J. C. Gunter, J. L. Bouldin, P. J. Vikesland, and J. A. Steevens. 2010. Fractionating nanosilver: Importance for determining toxicity to aquatic test organisms. Environmental Science and Technology 44(24): 9571-9577.

Lowry, G. V., K. B. Gregory, S. C. Apte, and J. R. Lead. 2012. Transformations of nanomaterials in the environment. Environmental Science Technology 46(13): 6893-6899.

McLaughlin, J., and J.-C. J. Bonzongo. 2012. Effects of natural water chemistry on nanosilver behavior and toxicity to Ceriodaphnia dubia and Pseudokirchneriella subcapitata. Environmental Toxicology and Chemistry 31(1): 168-175 .

Mebane, C. A. 2008. The accuracy and protectiveness of Biotic Ligand Model (BLM) toxicity predictions with copper, update. In Proceedings, Workshop on Biotic Ligand Model Principles and Applications, 12-14 May, Ontario, Canada: Wilfrid Laurier University, Waterloo.

Morgan, I. J., R. P. Henry, and C. M. Wood. 1997. The mechanism of acute silver nitrate toxicity in freshwater rainbow trout (Oncorhynchus mykiss) is inhibition of gill $\mathrm{Na}^{+}$and $\mathrm{Cl}^{-1}$ transport. Aquatic Toxicology 38(1-3): 145-163. 
Newton, K. M., H. L. Puppala, C. L. Kitchens, V. L. Colvin, and S. J. Klaine. 2013. Silver nanoparticle toxicity to Daphnia magna is a function of dissolved silver concentration. Environmental Toxicology and Chemistry 32(10): 2356-2364.

Nickel Producers Environmental Research Association (NiPERA) Inc. 2015. Nickel environmental risk assessment fact sheet 1: Data compilation, selection, and derivation of PNEC values for the freshwater compartment. http://www.nipera.org/en/EnvironmentalScience/FS1FreshwaterEffects.aspx.

Powers, C. M., T. A. Slotkin, F. J. Seidler, A. R. Badireddy, and S. Padilla. 2011. Silver nanoparticles alter zebrafish development and larval behavior: Distinct roles for particle size, coating and composition. Neurotoxicology and Teratology 33(6): 708-714.

Powers, C. M., J. Yen, E. A. Linney, F. J. Seidler, and T. A. Slotkin. 2010. Silver exposure in developing zebrafish (Danio rerio): Persistent effects on larval behavior and survival. Neurotoxicology and Teratology 32(3): 391-397.

Wood, C. M., R. C. Playle, and C. Hogstrand. 1999. Physiology and modeling of mechanisms of silver uptake and toxicity in fish. Environmental Toxicology and Chemistry 18(1): 71-83.

Yeo, M.-K., and M.-S. Kang. 2008. Effects of nanometer sized silver materials on biological toxicity during zebrafish embryogenesis. Bulletin of the Korean Chemical Society 29(6): 1179-1184.

NOTE: The contents of this technical note are not to be used for advertising, publication, or promotional purposes. Citation of trade names does not constitute an official endorsement or approval of the use of such products. 